\title{
PENGEMBANGAN MEDIA FLASHCARD PADA MATERI PYTHAGORAS BAGI SISWA KELAS VIII SMP
}

\author{
Rendy Wijayanto', Sutriyono² \\ ${ }^{1,2}$ Pendidikan Matematika,Universitas Kristen Satya Wacana, 202014084@student.uksw.edu
}

\section{INFO ARTIKEL}

Riwayat Artikel:

Diterima: 07-03-2018

Disetujui: 23-03-2018

\section{Kata Kunci:}

Flashcard

Pythagoras

Pengembangan

\section{ABSTRAK}

\begin{abstract}
Abstrak: Penelitian ini bertujuan untuk mengetahui apakah media flashcard valid, praktis, dan efektif digunakan dalam pembelajaran matematika. Subjek penelitian ini adalah siswa kelas VIII SMP N 3 Salatiga sebanyak 26 siswa. Jenis penelitian ini adalah pengembangan dengan model ADDIE. Hasil penelitian menunjukkan bahwa flashcard valid dengan nilai validitas materi sebesar $90.00 \%$ (sangat baik) dan validitas tampilan sebesar $84.74 \%$ (sangat baik) serta praktis dengan nilai kepraktisan sebesar $81.54 \%$ (baik). Selain itu, flashcard juga dapat meningkatkan hasil belajar dengan nilai $\mathrm{N}$-Gain sebesar 0.66 yang termasuk kategori peningkatan sedang dan mendapat respons positif dari siswa sehingga flashcard efektif digunakan dalam pembelajaran.

Abstract: This research is aimed to know whether flashcard is valid,practical, and effective to be used in Math learning. The subject of this research is eight grade student of SMP N 3 Salatiga. The kind of the research is ADDIE model development. The result of the research showed that flashcard is valid with the material validity of $90.00 \%$ (very good) and the display validity of $84.74 \%$ (very good) also practical with the practicity score of $81.54 \%$ (good). Besides, flashcard can also improve the learning outcomes with $N$-Gain score of 0.66 which is included into medium improvement category and gets the positive responds from students so flashcard is effective to be used in the teaching and learning.
\end{abstract}

\section{A. LATAR BELAKANG}

Pelajaran matematika sangatlah penting diajarkan di sekolah dasar sampai dibangku kuliah, bahkan dimasukkan dalam ujian nasional. Anggapan bahwa matematika adalah pelajaran yang hanya selalu berkaitan dengan angka-angka dan hitung-hitungan yang membosankan, melelahkan, bahkan sulit dicerna oleh otak. Dengan berbagai masalah yang terjadi dilapangan, peserta didik merasa terbebani dengan pelajaran matematika. Pemikiran-pemikiran yang demikianlah yang mempersulit peserta didik dalam memahami pelajaran matematika. Masalah seperti ini yang memotivasi guru untuk membuat media yang berisikan latihan soal dengan unsur joyfull guna mempermudah pemahaman siswa tentang suatu materi, seperti materi Pythagoras.

Menurut Kline dalam Pitajeng (2006: 1) menyatakan bahwa belajar akan efektif jika dilakukan dalam suasana yang menyenangkan. Salah satu cara yang dapat digunakan untuk menciptakan suasana belajar yang menyenangkan dengan menggunakan media, dasar pertimbangan menggunakan media yaitu dapat memenuhi kebutuhan atau mencapai tujuan yang diinginkan atau tidak. Mc. Connel (1974) mengatakan bila media itu sesuai pakailah, "If The medium Fits, Use It!". Salah satu media yang dapat diterapkan agar pembelajaran menarik adalah menggunakan media flashcard.
Flashcard merupakan kartu-kartu bergambar yang dilengkapi kata-kata, yang diperkenalkan oleh Glenn Doman. Gambar-gambar pada flashcard dikelompokkelompokkaan antara lain seri bintang, buah-buahan pakaian, warna bentuk-bentuk angka dan sebaginya. Menurut Doman (1991), flashcard dapat diberikan kepada anak sebagai sebuah permainan mengenal huruf dan katakata. Gambar-gambar flashcard yang menarik dengan warna-warni menyolok akan disukai anak-anak, sehingga para guru dan orang tua bisa mengajak mereka bergembira, bermain dan belajar dalam cara yang sederhana. Menurut Kasihani (2007) flashcards are teaching aids as picture paper which has $25 \times 30$. The pictures is made by hand, pictures or photo which is stick on the flashcard. Sependapat dengan Kasihani Dini Indriana (2011) juga mengungkapkan bahwa flashcard adalah media pembelajaran dalam bentuk kartu bergambar yang ukurannya seukuran postcard atau sekitar $25 \times 30 \mathrm{~cm}$. Menurut Arsyad (2011:3) flashcard adalah kartu kecil yang berisi gambar, teks, atau tanda symbol yang mengingatkan atau mengarahkan siswa kepada sesuatu yang berhubungan dengan gambar. Flashcard biasanya berukuran $8 \mathrm{~cm} \times 12 \mathrm{~cm}$, atau dapat disesuaikan dengan besar kecilnya kelas yang dihadapi.

Penelitian Siti Fatimah (2014) telah mengembangkan media flashcard untuk siswa kelas II di MI MA'ARUF SENDANG KULON PROGO. Media flashcard yang dihasilkan 
berupa kartu permainan yang berukuran $6 \mathrm{~cm} \times 9 \mathrm{~cm}$ yang memuat petunjuk permainan / penggunaan secara umum dan langkah-langkah peserta didik dalam menggunakan media flashcard, yang menunjukkan bahwa media flashcard valid dan sangat pratis digunakan. Flashcard yang dihasilkan memperoleh validitas ahli materi dengan nilai baik dengan skor 4 dengan konversi skor 4,00 sedangkan penilaian ahli media adalah baik dengan skor 4,12 dengan konversi skor 4,12 dengan hasil rerata yang didapat dari ahli tersebut 4,06. Dengan demikian hasil rerata ditinjau dari ahli materi dan ahli media adalah Baik.

Hal ini sesusai dengan penelitian Hestiana Ikhwati (2014) juga mengembangkan media flashcard dengan keefektifan media $84,17 \%$ sesuai kriteria menurut BSNP dan ketuntasan klasikal yang diperoleh siswa pada saat percobaan lapangan mencapai $92 \%$.

Berdasarkan penelitian diatas, muncul suatu ide untuk mengembangkan media yang dikembangkan dari media flashcard. Model pengembangan yang digunakan dalam penelitian ini adalah ADDIE (Analysis, Design, Development, Implementation, Evaluation). Penelitian ini bertujuan untuk mengembangkan media flashcard pada materi Pythagoras bagi siswa kelas VIII SMP.

\section{B. METODE PENELITIAN}

Penelitian ini merupakan jenis penelitian Research and Development (R\&D). Penelitian pengembangan adalah metode penelitian yang digunakan untuk menghasilkan produk tertentu dan menguji keefektifan produk tersebut (Sugiyono, 2014: 297). Produk yang dihasilkan berupa media pembelajaran berupa flashcard pada materi Pythagoras untuk siswa SMP kelas VIII. Penelitian ini menggunakan model pengembangan untuk media pembelajaran yang mengacu pada jenis pengembangan model ADDIE. Adapun tahap-tahap dalam model pengembangan ADDIE adalah sebagai berikut.

1. Analyze (analisis)

Tahap analisis bertujuan mengumpulkan informasi apa yang diperlukan siswa SMP dalam pembelajaran Pythagoras.

2. Design (disain / perancangan)

Flashcard dirancang dan dikembangkan berdasarkan data yang didapat pada tahap analisis.

3. Development (pengembangan)

Tahap pengembangan merupakan tahap dimana Flashcard dibuat berdasarkan design yang telah dibuat sebelumnya.

4. Implementation (implementasi)

Tahap ini dilakukan untuk menguji coba terhadap Flashcard yang telah dibuat sebelumnya. Uji coba dilaksanakan di sekolah yang dijadikan sebagai subjek penelitian yaitu siswa VIII di SMP N 3 Salatiga.
5. Evaluation (evaluasi)

Tahap evaluasi merupakan tahap memberikan nilai terhadap flashcard. Evaluasi meliputi hasil belajar siswa setelah penggunaan media flashcard, keefektifan dan kepraktisan media, dan pendapat siswa tentang penggunaan flashcard.

Analisis pada yang dilakukan pada penelitian ini adalah untuk menentukan validitas, kepraktisan, serta keefektifan flashcard. Selain itu, soal yang digunakan juga dianalisis validitasnya sehingga soal yang diuji cobakan kepada siswa merupakan soal yang telah valid.

1. Analisis Data Validasi dan Lembar Kepraktisan

a. Menentukan rata-rata berdasarkan data yang telah diperoleh dari angket.

b. Menentukan persentase penilaian tiap aspek kriteria dalam masing-masing komponen flashcard.

$$
P P=\frac{\text { skor hasil penilaian }}{\text { skor maks }} \times 100
$$

c. Mengubah persentase nilai pada flashcard. menjadi nilai kualitatif sesuai dengan kategori penilaian dengan ketentuan pada Tabel 1 .

TABEL 1.

\section{KETENTUAN PENILAIAN VALIDASI DAN KEPRAKTISAN}

\begin{tabular}{ccc} 
No. & Rentang Skor $(\mathbf{x})$ & Kategori \\
\hline 1. & $x>84 \%$ & Sangat Baik \\
2. & $68 \%<x \leq 84 \%$ & Baik \\
3. & $52 \%<x \leq 68 \%$ & Cukup \\
4. & $36 \%<x \leq 52 \%$ & Kurang \\
5. & $x \leq 36 \%$ & Sangat Kurang
\end{tabular}

2. Keefektifan flashcard Matematika

Keefektifan flashcard ditentukan berdasarkan hasil belajar posttest serta berdasarkan hasil lembar pendapat siswa. Hasil lembar pendapat siswa dianalisis secara kualitatif. Data hasil belajar posttest siswa yang telah terkumpul kemudian dianalisis signifikansi peningkatannya dari nilai pretest yang dihitung dengan rumus $\mathrm{N}-$ Gain berikut:

$$
N-\text { Gain }=\frac{\text { skor posttest }- \text { skor pretest }}{\text { skor maksimum }- \text { skor pretest }}
$$

Kategori N-Gain dapat dilihat pada Tabel 2.

TABEL 2

\begin{tabular}{ccc}
\multicolumn{3}{c}{ KLASIFIKASI KATEGORI N-GAIN } \\
No. & Skor N-Gain & Kategori \\
\hline 1. & $G \geq 0,70$ & Peningkatan Tinggi \\
2. & $0,30 \leq G$ & Peningkatan Sedang \\
& $<0,70$ & \\
3. & $G<0,30$ & Peningkatan Rendah
\end{tabular}




\section{Analisis Data Soal Posttest}

Sebelum instrumen digunakan untuk memperoleh data penelitian instrumen, maka intrumen yang berupa soal tes akan diujicobakan terlebih dahulu untuk memastikan instrumen tersebut valid untuk digunakan. Validitas merupakan derajat ketepatan antara data yang terjadi pada objek penelitian dengan daya yang dapat dilaporkan oleh peneliti. Dengan demikian data yang valid adalah data yang sesungguhnya terjadi pada objek penelitian (Sugiyono, 2011: 363).

\section{HASIL DAN PEMBAHASAN}

Penelitian ini mengembangkan flashcard pada materi Pythagoras. Proses pembuatan dilakukan sesuai dengan alur model pengembangan ADDIE. Berdasarkan model pengembangan ADDIE, proses pembuatan flashcard adalah sebagai berikut ini.

1. Analyze (Analisis)

Proses pengembangan media ini melalui tahap analisis baik analisis kebutuhan maupun analisis kinerja. Hasil analisis kebutuhan menyimpulkan diperlukannya media yang dapat digunakan untuk mengemas latihan soal menjadi suatu kegiatan yang menyenangkan, salah satu caranya menggunakan media flashcard. Selain itu, diketahui bahwa flashcard sangat efektif jika digunakan sebagai media pembelajaran. Hal ini dapat dibuktikan dengan penelitian yang dilakukan Siti Fatimah (2014) telah mengembangkan media flashcard untuk siswa kelas II di MI MA'ARUF SENDANG KULON PROGO yang menunjukkan bahwa media flashcard valid dan sangat pratis digunakan. Flashcard yang dihasilkan memperoleh validitas ahli materi dengan nilai baik dengan skor 4 dengan konversi skor 4,00 sedangkan penilaian ahli media adalah baik dengan skor 4,12 dengan konversi skor 4,12 dengan hasil rerata yang didapat dari ahli tersebut 4,06. Dengan demikian hasil rerata ditinjau dari ahli materi dan ahli media adalah Baik.

2. Design (Desain)

a. Menentukan Kompetensi Dasar

Penelitian ini dilaksanakan di SMP N 3 Salatiga yang menggunakan kurikulum K13. Materi Pythagoras terdiri dari 2 kompetensi dasar yaitu menggunakan teorema Pythagoras untuk menentukan panjang sisi-sisi segitiga siku-siku dan memecahkan masalah pada bangun datar yang berkaitan dengan Pythagoras.

b. Menentukan Tujuan Belajar

Berdasarkan kompetensi dasar di atas, maka tujuan pembelajaran yang ingin dicapai dalam pengembangan flashcard ini adalah siswa mempu menggunakan teorema Pythagoras untuk menentukan panjang sisi-sisi segitiga siku-siku dan memcahkan masalah pada bangun datar yang berkaitan dengan teorema Pythagoras

3. Development (Pengembangan)

a. Memilih Strategi Pembelajaran

Berdasarkan hasil dari tahap analisis, flashcard sangat diminati dan juga efektif apabila digunakan sebagi media dalam pembelajaran matematika. Oleh karena itu, dalam penelitian ini akan menggembangkan flashcard dimana flashcard ini nantinya akan dibuat dalam bentuk cetak hardfile.

b. Memilih Materi Pembelajaran

Flashcard menggunakan materi Pythagoras dan telah disesuaikan dengan kegiatan belajar mengajar di kelas VIII SMP N 3 Salatiga sehingga dapat digunakan sebagi alat bantu evaluasi belajar bagi siswa.

c. Membuat Flashcard

Langkah awal yang dilakukan dalam membuat flashcard adalah design background, kemudian membuat sketsa berdasarkan design background yang telah ditentukan. Sketsa yang telah jadi kemudian di-design dan dilakukan finishing berupa pemberian teks, gambar dan juga pewarnaan. Proses finishing dilakukan dengan menggunakan software pengolah grafis CorelDRAW X7. Flashcard terdiri atas beberapa komponen yaitu sampul, dan soal latihan. Sampul berisi informasi mengenai judul flashcard, materi yang diangkat, dapat dilihat pada Gambar ।.

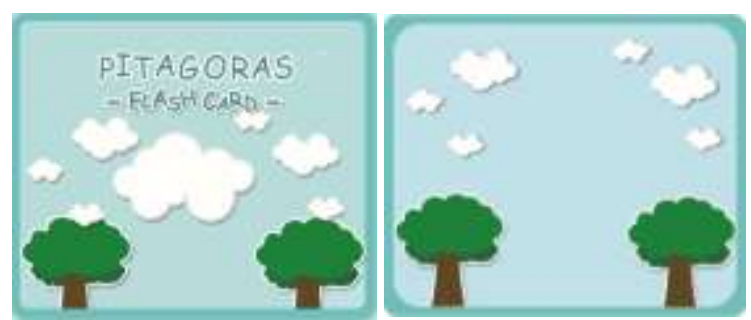

Gambar 1. Sampul Flashcard

Berisi soal yang nantinya bagian depan flashcard terdapat gambar dan di belakang nya terdapat soal tentang gambar tersebut Contoh gambar dan soal dapat dilihat pada Gambar r.
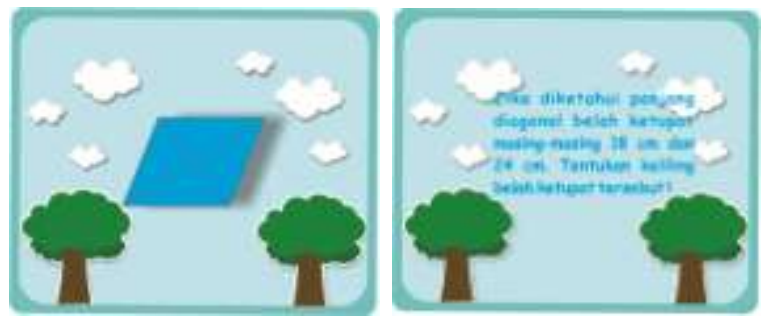

Gambar 2. Soal Flashcard 
Flashcard berisi soal-soal tentang materi Pythagoras yang berjumlah 25 soal. Flashcard dapat digunakan dengan cara mengelompokkan siswa yang berjumlah 26 menjadi 5 kelompok. Masing- masing kelompok diberikan 1 buah flashcard kemudian setelah selesai mengerjakan, soal tersebut dibahas di depan kelas bersama-sama. Bagi kelompok yang menjawab dengan benar mendapat 1 poin, sedangkan yang menjawab salah tidak akan mendapat poin. Setelah itu dibagikan soal kedua dan seterusnya sampai soal flashcard habis.

4. Implementation (Implementasi)

a. Validasi Ahli

Validasi ahli adalah tahap untuk validasi flashcard oleh validator. Proses validasi menggunakan instrumen lembar validasi yang terdiri dari dua aspek, yaitu aspek materi dan aspek tampilan. Validasi dilakukan untuk memperoleh kritik dan saran dari validator serta untuk menentukan apakah media flashcard layak digunakan dalam penelitian. Kritik dan saran dari validator menjadi acuan untuk perbaikan flashcard.

b. Revisi Produk

Revisi produk dilakukan sesuai dengan kritik dan saran yang diberikan oleh validator. Saran, kritik, dan tindak lanjut diuraiakan pada Tabel 3.

TABEL 3

SARAN, KRITIK, DAN TINDAK LANJUT

\begin{tabular}{clrl} 
No. & \multicolumn{2}{c}{ Kritik dan Saran } & \multicolumn{1}{c}{ Tindak Lanjut } \\
\hline 1. & Pada & soal & Memberikan \\
& sebaiknya diberi & warna dan \\
warna yang & menambahkan \\
berbeda dari warna & contoh soal \\
background agar & \\
lebih menarik &
\end{tabular}

2. Font pada bagian Mengganti font soal sulit untuk menjadi font yang dibaca dan mudah dibaca dan membuat pusing. dipahami.

Lebih baik diganti

dengan font

standar supaya

konsep lebih

mudah dipahami.

3. Latihan soal Menambahkan diperbanyak jumlah soal latihan

4. Gunakan bahasa Bahasa sengaja baku karena ini dibuat tidak baku merupakan media agar tidak kaku pembelajaran. dan terkesan santai sehingga siswa lebih nyaman ketika membaca.
5. Evaluation (Evaluasi)

a. Analisis Data Validasi

Validasi flashcard ditentukan berdasarkan penilaian validator yang terdiri dari dua aspek, yaitu aspek materi dan aspek tampilan. Data hasil validasi dapat dilihat pada Tabel 4 .

TABEL 4

HASIL VALIDASI

\begin{tabular}{|c|c|c|c|c|}
\hline \multirow{2}{*}{ No. } & \multicolumn{2}{|c|}{ Materi } & \multicolumn{2}{|c|}{ Tampilan } \\
\hline & Val 1 & Val 2 & Val 1 & Val 2 \\
\hline 1 & 5 & 4 & 3 & 4 \\
\hline 2 & 4 & 4 & 5 & 5 \\
\hline 3 & 5 & 4 & 4 & 5 \\
\hline 4 & 4 & 5 & 4 & 4 \\
\hline 5 & 5 & 4 & 4 & 4 \\
\hline 6 & 4 & 4 & 3 & 4 \\
\hline 7 & 5 & 5 & 5 & 4 \\
\hline 8 & 4 & 5 & 5 & 5 \\
\hline 9 & 5 & 5 & 5 & 4 \\
\hline 10 & & & 3 & 4 \\
\hline 11 & & & 4 & 4 \\
\hline 12 & & & 5 & 3 \\
\hline 13 & & & 5 & 4 \\
\hline 14 & & & 3 & 3 \\
\hline 15 & & & 4 & 5 \\
\hline 16 & & & 4 & 4 \\
\hline 17 & & & 5 & 5 \\
\hline 18 & & & 4 & 5 \\
\hline 19 & & & 5 & 5 \\
\hline Jumlah & 41 & 40 & 80 & 81 \\
\hline Rata-rata & & & 80 & \\
\hline Validitas & & $\%$ & 84.7 & $\%$ \\
\hline Keterangan & Sang & Baik & San & at Baik \\
\hline
\end{tabular}

Data hasil validasi kemudian dianalisis sebagai berikut:

$$
\begin{array}{r}
P A M=\frac{40.50}{45} \times 100 \% \\
=90.00 \% \\
P A T=\frac{80.50}{95} \times 100 \\
=84.74 \%
\end{array}
$$

Berdasarkan data hasil validasi diatas diperoleh persentase rata-rata sebesar $90.00 \%$ dan termasuk dalam kategori sangat baik untuk aspek materi sedangkan untuk aspek tampilan diperoleh persentase rata-rata sebesar $84.74 \%$ dan termasuk dalam kategori sangat baik.

b. Analisis Data Kepraktisan

Kepraktisan flashcard ditentukan berdasarkan instrumen lembar kepraktisan dengan responden guru matematika kelas VIII siswa siswa SMP N 3 Salatiga yang menggunakan Data hasil lembar kepraktisan dapat dilihat pada Tabel 5. 
TABEL 5.

\begin{tabular}{cc} 
HASIL LEMBAR KEPRAKTISAN \\
\hline Penilai & Skor \\
Validator 1 & 16 \\
Validator 2 & 16 \\
Validator 3 & 16 \\
Validator 4 & 17 \\
Validator 5 & 13 \\
Validator 6 & 15 \\
Validator 7 & 17 \\
Validator 8 & 20 \\
Validator 9 & 18 \\
Validator 10 & 16 \\
Validator 11 & 14 \\
Validator 12 & 15 \\
Validator 13 & 19 \\
Jumlah & 212 \\
Rata-rata & 16.31 \\
\hline
\end{tabular}

Data hasil lembar kepraktisan kemudian dianalisis sebagai berikut:

$$
\begin{aligned}
\text { Praktis } & =\frac{16.31}{20} \times 100 \% \\
& =81.54 \%
\end{aligned}
$$

Berdasarkan data hasil dari lembar kepraktisan diperoleh persentase rata-rata sebesar $81.54 \%$ dan termasuk dalam kategori baik.

\section{c. Analisis Data Keefektifan}

Keefektifan flashcard ditentukan berdasarkan hasil posttest siswa kelas VIII. Hasil dari pretest dan posttest dapat dilihat pada Tabel 6 .

TABEL 6.

HASIL PRETEST DAN POSTTEST Pretest

\section{Postest}

\begin{tabular}{cccc}
\hline Jumlah & Rata-rata & Jumlah & Rata-rata \\
612 & 29 & 1,594 & 76
\end{tabular}

Data hasil pretest dan posttest siswa yang telah terkumpul kemudian dianalisis signifikansi peningkatannya dengan menggunakan rumus $\mathrm{N}$ Gain berikut:

$$
\begin{gathered}
N-\text { Gain }=\frac{\text { skor posttest }- \text { skor pretest }}{\text { skor maksimum -skor pretest }} \\
N-\text { Gain }=\frac{1,594-612}{2,100-612} \\
N-\text { Gain }=0.66
\end{gathered}
$$

Berdasarkan perhitungan menggunakan rumus $\mathrm{N}$-Gain diperoleh hasil belajar kelas VIII mengalami peningkatan sebesar 0.66 yang termasuk dalam kategori peningkatan sedang. Hasil analisis pendapat siswa menunjukkan bahwa flashcard membantu siswa dalam belajar matematika. Tampilan flashcard sangat menarik bagi siswa dan memudahkan dalam belajar. Selain itu, flashcard juga menarik bagi siswa. Secara keseluruhan flashcard mendapat respons positif dari siswa dan efektif digunakan dalam pembelajaran matematika.

\section{SIMPULAN DAN SARAN}

Pengembangan flashcard disusun dengan menggunakan software CorelDRAW X7 dan telah melalui tahap validasi sangat baik dari aspek materi maupun aspek tampilan. Berdasarkan hasil validasi diperoleh persentase kevalidan aspek materi sebesar $90.00 \%$ dan termasuk dalam kategori sangat baik serta aspek tampilan sebesar $84.74 \%$ dan termasuk dalam kategori sangat baik sehingga flashcard valid digunakan dalam pembelajaran. Kepraktisan yang diperoleh berdasarkan analisis lembar kepraktisan diperoleh persentase sebesar $81.54 \%$ dan termasuk dalam kategori baik sehingga flashcard praktis digunakan dalam pembelajaran. Berdasarkan hasil posttest yang telah dilakukan menunjukkan bahwa terjadi peningkatan sebesar 0.66 dan termasuk dalam kategori peningkatan sedang. Hasil analisis lembar pendapat siswa menunjukkan bahwa flashcard membantu siswa dalam belajar dan mendapat respons yang positif dari siswa. Oleh karena itu, flashcard efektif digunakan dalam pembelajaran.

Mengingat media ini valid, praktis dan efektif digunakan dalam pembelajaran maka disarankan untuk mengembangkan media flashcard ini dalam mata pelajaran lain agar dapat meningkatakan nilai akademik siswa dan motivasi siswa.

\section{UCAPAN TERIMA KASIH}

Penulis mengucapkan terimakasih kepada Prof. Dr. Sutriyono, M.Sc., Ph.D. selaku pembimbing yang senantiasa memberikan bimbingan, nasehat, dan motivasi kepada penulis sehingga penelitian ini dapat terselesaikan dengan baik. Serta penulis juga mengucapkan terimakasih kepada kedua orang tua yang senantiasa memberikan nasehat dan motivasi kepada penulis.

\section{DAFTAR RUJUKAN}

[1] Pitajeng. 2006. Pembelajaran Matematika Yang Menyenangkan. Jakarta: Depdiknas Dirjen Perguruan Tinggi Direktorat Ketenagaan.

[2] Sadiman, Arif, dkk. 1986. Media Pendidikan. : pengertian, pengembangan, dan pemanfaatannya. Jakarta: CV RAJAWALI.

[3] Sugiyono. 2011. Metode Penelitian Pendidikan Pendekatan Kuantitatif, Kualitatif, dan R\&D. Bandung: Alfabeta. 
[4] Sadiman, Arif, dkk. 2008. Media Pendidikan. : Pengertian, Pengembangan, dan Pemanfaatannya. Jakarta: CV RajaGrafindo Persada.

[5] Ikhwati, Hestiana. 2014. "Pengembangan Media Flashcard IPA Terpadu Dalam Pembelajaran Model Kooperatif Tipe Students Teams Achievement Divisoins (STAD) Tema Polusi Udara". http://journal.unnes.ac.id/artikel_sju/usej/3344 [diakses 16 Desember 2017, 10.31].

[6] Azhar Arsyad, (2011). Media Pembelajaran. Jakarta: PT. Rajawali Press.

[7] Indriana, Dina. 2011. Ragam Alat bantu Media Pengajaran. Yogyakarta: Diva Press.

\section{PROFIL PENULIS UTAMA}

Penulis bernama lengkap "Rendy Wijayanto". Lahir di Salatiga Provinsi Jawa Tengah pada tanggal 16 JuLi 1995 dari pasangan Nuryadi dan Sumiyati. Penulis adalah anak pertama dari 2 bersaudara. Pendidikan sekolah dasar dimulai dari SDN 1 BLOTONGAN Kecamatan Sidorejo pada tahun 2001-2007. Setelah itu melanjutkan pendidikan sekolah menengah ke MTs N Salatiga pada tahun 2007 2010 dan terakhir di SMAN 3 Salatiga pada tahun 2010 2013. Kemudian penulis melanjutkan studi ke perguruan tinggi di Program Studi Pendidikan Matematika FKIP UKSW pada tahun 2014. Kritik, saran, maupun hal-hal yang berkaitan dengan kelanjutan atau pengembangan dari hasil penelitian ini bisa dikirim ke email penulis di : 202014084@student.uksw.edu. 